\title{
A metodologia WEBQUEST no contexto das questões de gênero: experiências de educadoras em debate
}

\author{
The WEBQUEST methodology in the context of gender issues: \\ experiences of educators in debate \\ Jean Pablo Guimarães Rossi ${ }^{1}$ \\ Fabiane Freire França ${ }^{2}$
}

Resumo: Neste artigo, extraído de uma pesquisa em âmbito de pósgraduação já concluída, temos como objetivo analisar as experiências de quatro educadoras frente à utilização da WebQuest (WQ), com o intuito de discutir como esta metodologia pode ser válida nas práticas pedagógicas, no que tange às questões de gênero. Para tanto, produzimos uma WQ intitulada Gênero e Diversidade na Escola, disponibilizada a partir de um curso ofertado durante o periodo de Formação Continuada para professoras/es atuantes da rede básica de ensino do município de Iretama, estado do Paraná. Posteriormente, uma das escolas do município foi selecionada para que realizássemos a proposta-convite de aplicação da WQ, culminando no consentimento e participação de quatro educadoras na pesquisa. Desta maneira, ancoradas/os na perspectiva teórica dos Estudos de Gênero, temos como fontes de análise, as experiências relatadas pelas participantes da

\footnotetext{
${ }^{1}$ Doutorando pelo Programa de Pós-Graduação em Educação da Universidade Estadual de Maringá (PPE-UEM). Mestre pelo Programa de Pós-Graduação Interdisciplinar Sociedade e Desenvolvimento, Pós-Graduado em Aprendizagem e Desenvolvimento nos Anos Iniciais da Educação Básica e membro do Grupo de Estudo e Pesquisa em Educação, Diversidade e Cultura (GEPEDIC/Cnpq) pela UNESPAR/Campus de Campo Mourão. Bacharel em Psicologia pela UNICAMPO. Docente da UNICAMPO - Faculdade União de Campo Mourão. 2 Doutora e Mestre em Educação pela Universidade Estadual de Maringá - UEM. Líder do Grupo de Estudo e Pesquisa em Educação, Diversidade e Cultura (GEPEDIC/Cnpq). Docente do colegiado de Pedagogia, do Programa de Pós-Graduação Interdisciplinar Sociedade e Desenvolvimento da UNESPAR/Campus de Campo Mourão e do Programa de Pós-Graduação em Educação da Universidade Estadual de Maringá (PPE-UEM).
}

Interfaces da Educ., Paranaíba, v.11, n.32, p. 213- 243, 2020 
pesquisa com a WQ, por meio dos questionários finais. Os resultados apontaram para a abertura que esta metodologia pode oferecer, no sentido de subsidiar o trabalho docente, incitar questionamentos e estabelecer novos diálogos acerca das discussões de gênero. Além disso, também evidenciou a necessidade de um maior investimento na formação docente, uma vez que mostrou a existência de alguns entraves nas respostas das educadoras.

Palavras-chave: Gênero. WebQuest. Formação Docente.

Abstract: In this article, from the research of post-graduation already finished, we aim to analyze the experiences of four educators with the use of WebQuest, to discuss how this methodology can be valid in the pedagogical practice, related to gender issues. Therefore, we produce a WQ named Gender and Diversity in the school, made available from the course offered during the Continued Education period to teachers actives in the basic network from Iretama city, Paraná state. Posteriorly, one of school from the city was chosen to carry out the application invitation proposal of WQ. This culminated in the consent and participation of four educators in the research. This way has a fundamental basis for the Gender Studies, we have as analysis source the experiences related by participants of research with WQ, through final questionnaires. The results pointed openness that this methodology can offer to subsidize the teaching work, incite questions and establish new dialogues about the gender discuss. Furthermore, it also evidenced the need for more investment in teaching formation, is that it showed the existence of some obstacles in the educators' answers.

Keywords: Gender. WebQuest. Teaching Formation.

\section{Introdução}

Neste trabalho, apresentamos resultados oriundos de uma pesquisa concluída no ano de 2019, vinculada à Pós-Graduação em Desenvolvimento e Aprendizagem nos Anos Iniciais da Educação Básica e ao Grupo de Estudo 
e Pesquisa em Educação, Diversidade e Cultura (GEPEDIC/CNPq), ambos da Universidade Estadual do Paraná/Campus de Campo Mourão. Nosso objetivo é analisar as experiências de quatro educadoras, atuantes de uma rede básica de ensino, frente à utilização da WebQuest Gênero e Diversidade na Escola com suas alunas e alunos.

Nos últimos anos, são muitos os pesquisadores e pesquisadoras que têm se dedicado a retratar as dificuldades que educadoras/es têm enfrentado no que tange a abordagem das questões de gênero em suas práticas pedagógicas (FIGUEIRÓ, 2014; FRANÇA, 2016; 2017; LEITE, 2015; LOURO; 2011; MAIO, 2011; MARTELLI, 2011; YAZLLE; FERNANDES, 2009). Em parte, o receio em trabalhar as questões de gênero, encontra-se em déficit na própria formação, tanto inicial quanto continuada, que professoras e professores, pouco têm recebido. Tal fato pode reverberar em posturas, por vezes, discriminatórias e excludentes, que tendem a ignorar a diversidade existente no espaço escolar. Diante deste contexto, denotamos a urgência de buscarmos novas estratégias que consigam viabilizar que docentes gradativamente incorporem questões de gênero em suas práticas pedagógicas.

Pensando nesta conjuntura, contemplamos na metodologia WebQuest (WQ), uma alternativa pertinente para propormos no contexto de ensino e formação docente, no que tange as discussões de gênero. A WQ se trata de uma metodologia idealizada por Bernie Dodge, no ano de 1995, nos Estados Unidos. Caracteriza-se por ser uma página online, que contempla um processo de investigação orientada por meio de recursos da Internet, com a intenção de contribuir no processo de aquisição de um determinado conhecimento de maneira significativa. Para tanto, dentro da WQ a/o usuária/o é apresentada/o a uma ou mais tarefas à serem cumpridas no percurso de sua utilização, assim, a/o participante é um sujeito ativo na construção do conhecimento (BOTTENTUIT JUNIOR; COUTINHO, 2012; NASCIMENTO, 2018; PEREIRA, 2009; ROCHA, 2007; SILVA; BOTTENTUIT JUNIOR, 2014). 
Uma das vantagens encontradas na WQ "é o fato de que pode ser adaptada a uma grande variedade de assuntos, idade, níveis de aprendizado e a muitas áreas de conhecimento [...]" (ROCHA, 2007, p. 60), sendo este um dos fatores mais importantes para que pudéssemos propor esta pesquisa, haja vista a flexibilidade e acessibilidade que esta metodologia favorece. Dito isto, a fim de verificar como esta metodologia poderia se configurar como válida no ensino e na formação de professoras/es mediante as questões de gênero, produzimos a WebQuest Gênero e Diversidade na Escola'. Esta mesma WQ foi disponibilizada durante um curso intitulado: "Mulheres na Escola: uma metodologia para o trabalho de gênero", ofertado durante uma semana de Formação Continuada de professoras/es do município de Iretama, estado do Paraná, no ano de 2019. Em momento posterior, uma das escolas do referido municipio foi selecionada para que levássemos a proposta-convite de aplicação da WQ.

A partir das experiências de quatro educadoras frente à utilização da WQ, aqui temos como fontes de discussão, os questionários respondidos pelas participantes que prontamente, concordaram em participar desta pesquisa por meio da aplicação da WebQuest Gênero e Diversidade na Escola com suas respectivas turmas. Para a realização das análises desta pesquisa, nos ancoramos na perspectiva teórica dos Estudos de Gênero, em autoras como: Adichie (2015), Louro (1997; 2011), Figueiró (2014), França (2014; 2016; 2017) e Furlani (2013).

Estruturalmente, este artigo está organizado em três seções. $\mathrm{Na}$ primeira, abordamos o que é a metodologia WebQuest, bem como de que maneira ela pode se configurar como válida para a discussão de gênero em sala de aula. Na segunda seção, apresentamos o caminho que trilhamos durante o período de Formação Continuada com as/os docentes do município de Iretama - PR, até a realização da proposta-convite de aplicação em uma das escolas desta mesma cidade. Por fim, na terceira seção apresentamos e analisamos os dados oriundos dos questionários

\footnotetext{
${ }^{1}$ No processo de construção desta WQ, contamos a colaboração de Aline Fernanda Cordeiro e Sônia Maria Yassue Okido Rodrigues.

Interfaces da Educ., Paranaíba, v.11, n.32, p. 213- 243, 2020
} 
respondidos pelas participantes, por meio de suas experiências com o uso da WQ Gênero e Diversidade na Escola.

\section{A WebQuest como possibilidade de inserção da temática "gênero" em sala de aula}

Com esta primeira seção, temos por intuito responder a seguinte questão: como a metodologia WebQuest pode ser utilizada acerca das questões de gênero? Para tanto, nos pautamos nas pesquisas de diversas/os autoras/es que nos últimos anos têm se dedicado a mostrar como o déficit de formação para as questões de gênero, tanto inicial quanto continuada, oferecem lugar a resistências e interpretações equivocadas que culminam em práticas pedagógicas, muitas vezes, alicerçadas em concepções pessoais, crenças biomédicas, higienistas, religiosas e heteronormativas (FIGUEIRÓ, 2014; FRANÇA, 2016; 2017; LEITE, 2015; LOURO, 1997; 2011; MAIO, 2011; MARTELLI, 2011; YAZLLE; FERNANDES, 2009).

Autoras/es como Alós (2011) e Andrade (2013), denominam estas práticas como "pedagogias culturais", constituídas pelo atravessamento das diversas experiências pessoais de cada educadora/or e, consequentemente, atuam ditando o lugar da suposta "normalidade" e da "diferença". A escola, neste sentido, torna-se um dos espaços mais propícios de produção e disseminação de diversos estigmas, preconceitos e discriminações que, uma vez não trabalhados, tendem a excluir meninas e meninos que fogem da suposta "norma". Leite (2015, p. 79), por exemplo, sublinha que durante a trajetória de vida de cada professora/or, "ideologias religiosas, valores e crenças são construídos. Muitas dessas aprendizagens adquiridas nos espaços não formais podem acompanhar e reforçar a prática docente na escola".

Tal teorização, nos mostra a necessidade de continuarmos investindo na formação de professoras/es, a fim de des/re/construirmos as concepções destas/es profissionais, com o objetivo de que possam ser despertadas/os para a tomada de consciência da sua responsabilidade em torno da educação de gênero. Entretanto, esta formação não se dá alheia à sua Interfaces da Educ., Paranaíba, v.11, n.32, p. 213- 243, 2020 
atividade profissional, muito pelo contrário, acreditamos que o desenvolvimento da/o docente se dá em um processo contínuo, articulado entre a teoria e a práxis pedagógica (FIGUEIRÓ, 2014; FRANÇA, 2016; 2017; LEITE, 2015; LOURO, 2011; MAIO, 2011). É neste contexto que Figueiró (2014, p. 102) corrobora com esta afirmativa ao explicitar que,

O ensino, concebido como uma profissão impõe a necessidade de envolvimento dos professores num processo contínuo de formação [...] Em vez de se caracterizar como uma atividade puramente racional, tal qual uma técnica, é um tipo de fazer que se constitui como domínio da práxis, porque é histórico, incompleto e mutável. Assim, exige de cada educador um aprendizado constante (FIGUEIRÓ, 2014, p. 102).

Para Rocha (2007), os cursos de formação de professoras/es, constantemente, estão centrados na pura transmissão de conhecimentos técnicos orientados para a prática docente e que, uma vez internalizados pelas/os professora/es, operarão por si próprios. Assim, Rocha (2007, p. 15) também sinaliza que esta é uma ideia que não concebe a/o professora/or como uma/um produtora/or de saberes, o que em nosso entendimento "reduz significativamente a visão intelectual do professor enquanto formador de um indivíduo crítico". É preciso conceber a/o professora/or como uma/um profissional que no processo de ensino-aprendizagem é formadora/or, ao mesmo tempo em que também é formada/o, ou seja, é "a necessidade de compreender o professor como um profissional que também produz saberes em sua atuação e não simplesmente como um técnico e um transmissor" (FIGUEIRÓ, 2014, p. 106).

Pensando nas dificuldades encontradas pelas/os educadoras/es para a abordagem de gênero com suas/seus alunas/os, é que encontramos algumas pesquisas que constatam que parte deste déficit se dá em vista da "ausência de materiais pedagógicos que possam servir de subsídios para o trabalho de gênero e de sexualidade com as crianças” (LEITE, 2015, p. 115). Como foi constatado nos estudos de Leite (2015), mesmo entre as/os educadoras/es que apresentam interesse em iniciar o trabalho acerca das questões de gênero, muitas se sentem sem respaldo ou subsídios para tratar 
da temática em suas respectivas turmas. São estes, alguns dos elementos significativos que, na ausência de discussão dentro da formação das/os professoras/es, tendem a enrijecer as mesmas compreensões docentes e impedir um trabalho de gênero que seja mais efetivo.

Tendo este contexto em vista é que então defendemos a necessidade de buscarmos novas configurações de trabalho que tragam as questões de gênero para o cerne do debate e coopere para que docentes possam vencer as barreiras que dificultam o trabalho em sala (FIGUEIRÓ, 2014; FRANÇA, 2014). É neste processo de busca que pudemos contemplar, na metodologia WebQuest, uma possibilidade alternativa para subsídio da prática e da formação de educadoras/es para o trabalho em torno das questões de gênero e que culminou na construção de uma WQ intitulada Gênero e Diversidade na Escola.

A metodologia WQ surgiu no ano de 1995, idealizada por Bernie Dodge, professor de tecnologia educacional em San Diego University, nos Estados Unidos. O termo WebQuest, traduzido para a lingua portuguesa significa "Busca na Web" e caracteriza-se por tratar-se de uma metodologia online que se propõe a utilizar os recursos da Internet para a proposta de uma investigação orientada no processo de construção de um conhecimento (BOTTENTUIT JUNIOR; COUTINHO, 2012; NASCIMENTO, 2018; PEREIRA, 2009; ROCHA, 2007; SILVA; BOTTENTUIT JUNIOR, 2014). Além disso, a WQ tende a se configurar como uma proposta que engaje a/o usuária/o a ser um sujeito ativo no caminho de busca e produção dos saberes, como é afirmado por Rocha (2008, p. 5):

\footnotetext{
Navegar na internet pode ser um processo de busca de informações valioso na construção do conhecimento, gerando um rico ambiente interativo facilitador e motivador de aprendizagem, bem como pode ser um dispersivo e inútil coletar de dados sem relevância que não agregam qualidade pedagógica ao uso da rede. Webquest pretende ser uma metodologia de engajar alunos e professores num uso da internet voltado para o processo educacional, estimulando a pesquisa, o pensamento crítico, o desenvolvimento de professores e a produção de materiais.
} 
Portanto, a WQ não pretende ser uma mera página online com um conglomerado de informações dispersas e tão somente reunidas em único lugar. Nesta metodologia, as/os participantes são cuidadosamente guiadas/os por um caminho previamente estruturado e estabelecido por suas/seus idealizadoras/es. Exemplo disto são os elementos que a constituem e a diferenciam de outros exercícios orientados via Web. Por isto, estar bem ciente das especificidades que formam esta metodologia, pode ser muito pertinente para o sucesso de sua aplicação. Em suma, uma WQ deve conter cinco etapas principais, podendo ou não apresentar outras etapas, de acordo com as intenções de quem a construir, são elas: Página Inicial, Introdução, Tarefa, Processos, Avaliação, Considerações Finais (BOTTENTUIT JUNIOR; COUTINHO, 2012; NASCIMENTO, 2018; PEREIRA, 2009; ROCHA, 2007; SILVA; BOTTENTUIT JUNIOR, 2014).

- A "Página Inicial" é o cartão de visitas da WQ e para o conteúdo que será apresentado. Assim, Bottentuit Junior e Coutinho (2012, p. 75) ressaltam que por se tratar do primeiro momento de contato da/o usuária/o com a WQ, é pertinente uma "preocupação especial em escolher boas fotografias, imagens e letras para a sua capa, o autor de uma WebQuest também deverá ter esta mesma preocupação". Neste primeiro momento, apesar de breve, é relevante que nele estejam contidos os cumprimentos de boas-vindas a/ao usuária/o, os objetivos, a quem se destina, uma imagem alusiva ao que será abordado e o nome das/os autoras/es (BOTTENTUIT JUNIOR; COUTINHO, 2012; NASCIMENTO, 2018; PEREIRA, 2009; ROCHA, 2007; SILVA; BOTTENTUIT JUNIOR, 2014).

- A "Introdução" é o momento em que a/o participante deverá ser mobilizada/o em torno do conteúdo da temática que será trabalhada. Portanto, textos, vídeos, imagens e reportagens são bem-vindas neste momento, apesar de ser indicada certa cautela para que não se torne extensa e cansativa. Inclusive, é prudente que seja tomado o cuidado de não oferecer informações excessivas, a ponto que não aguce questionamentos que descentralizem do objetivo principal, à/ao usuária/o (BOTTENTUIT JUNIOR; COUTINHO, 2012; NASCIMENTO, 2018; PEREIRA, 2009; ROCHA, Interfaces da Educ., Paranaíba, v.11, n.32, p. 213-243, 2020 
2007; SILVA; BOTTENTUIT JUNIOR, 2014). Dessa forma: "embora a Introdução deva fornecer algumas breves informações sobre o tema a ser trabalhado, sugere-se manter um ar de mistério para aguçar a curiosidade [...] sobre o que irão encontrar nas páginas seguintes" (BOTTENTUIT JUNIOR; COUTINHO, 2012, p. 76).

- A "Tarefa" é a parte mais importante de uma WQ, pois estabelecerá a missão a ser cumprida pela/o participante, além de concretizar as intenções da/o autora/or (ROCHA, 2008). É plausivel pensar que a tarefa deve ser compativel aos objetivos da WQ construída, além de ser clara e exequível. Aqui se concentra um ponto importante para ponderação, uma vez que Bottentuit Junior e Coutinho (2012, p. 76) averiguaram que muitas autoras/es acabam errando neste item, pois propõem tarefas muito fáceis, extremamente complexas ou não compreensiveis para a/o usuária/o. Sendo este um momento relevante da WQ, "é muito importante rever a qualidade da tarefa proposta para verificar se ela realmente será capaz de promover a transformação da informação recolhida num novo conhecimento". Além de ser objetiva sobre o que a/o participante deverá realizar, mas o "como fazer" deve ser um processo de descoberta durante o caminho de sua resolução.

- O "Processo" diz respeito a verificação de todas as etapas a serem executadas durante o manuseio da WQ, momento este, que deve primar pela descrição mais clara possivel de todos os passos necessários para a conclusão de todo o processo, ou seja, é o passo a passo da WQ (BOTTENTUIT JUNIOR; COUTINHO, 2012; NASCIMENTO, 2018; PEREIRA, 2009; ROCHA, 2007; SILVA; BOTTENTUIT JUNIOR, 2014).

- A etapa de “Avaliação" é essencial dentro de uma WQ, uma vez que diz respeito à retomada ou a "retroação dos principais pontos da pesquisa, a fim de que possa saber quais pontos precisam ser melhorados e com isso contribuir ainda mais para a construção do seu conhecimento" (ROCHA, 2007, p. 75). Esta etapa pode ser realizada por meio de processos tanto qualitativos quanto quantitativos, contemplando questões descritivas e/ou objetivas. O importante é propiciar um momento para que a/o participante possa refletir em torno do conhecimento atingido, além de oferecer um Interfaces da Educ., Paranaíba, v.11, n.32, p. 213-243, 2020 
feedback a/ao autora/or da WQ (BOTTENTUIT JUNIOR; COUTINHO, 2012; NASCIMENTO, 2018; PEREIRA, 2009; ROCHA, 2007; SILVA; BOTTENTUIT JUNIOR, 2014).

- A "Conclusão" se refere a última etapa do processo e pode representar não o fechamento, mas a abertura para novas inquietações, outras questões e reunir sugestões para aperfeiçoar o aprendizado, pois uma WQ "poderá ser sempre um produto inacabado e estar sempre em fase de reconstrução. É importante sempre deixar as 'portas abertas' para outras verdades e facetas do conhecimento" (ROCHA, 2007, p. 75). Ademais, esta etapa pode ser aproveitada para convidar a/o usuária/o a retornar a WQ, além de propor para que divulgue com outras/os professoras/es, por meio do compartilhamento do link de acesso online, uma vez que é ideal que a WQ construída fique acessivel a quaisquer outras pessoas que tenham interesse em visitá-la e utilizá-la (BOTTENTUIT JUNIOR; COUTINHO, 2012; NASCIMENTO, 2018; PEREIRA, 2009; ROCHA, 2007; SILVA; BOTTENTUIT JUNIOR, 2014).

Tendo em vista a estrutura, componentes e possibilidades dentro desta metodologia, idealizamos e construímos a WebQuest Gênero e Diversidade na Escola, com o propósito de contribuir para a formação de educadores e educadoras que estivessem atuando na rede básica de ensino, a fim de convidá-las/los para o debate sobre as questões de gênero com suas alunas e alunos. Tendo este objetivo em vista e buscando mecanismos que impulsionassem esta discussão, a WQ que desenvolvemos contém uma expressividade de possibilidades didático-pedagógicas que vão desde dinâmicas e brincadeiras, até sugestões de bibliografias e filmes para uso em sala de aula. Para tanto, consideramos plausivel a elaboração de mais três seções para além das etapas já previstas na WQ - abordadas anteriormente são elas: Sugestões de vídeos e filmes; Dinâmicas e Brincadeiras; Sugestões de liuros $e$ histórias. Estas três seções são partes essenciais para o cumprimento da tarefa proposta nesta WQ, como veremos adiante. 


\section{Recorte demonstrativo das seções: sugestões de videos e filmes e Sugestões de livros e histórias ${ }^{2}$}

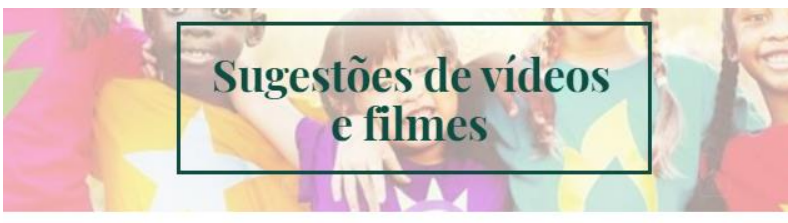

Suzestões de vídeos para o lrahalho de gênero em sola de auli:
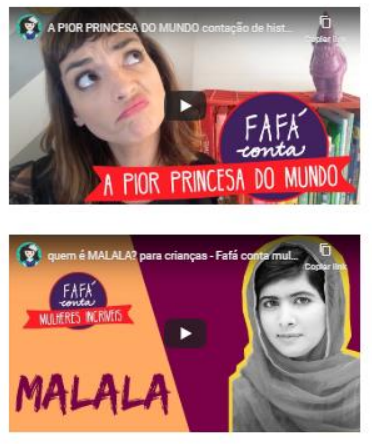
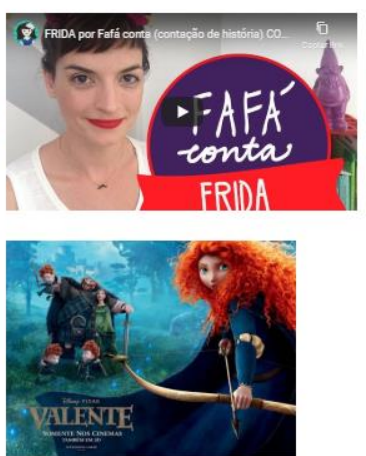

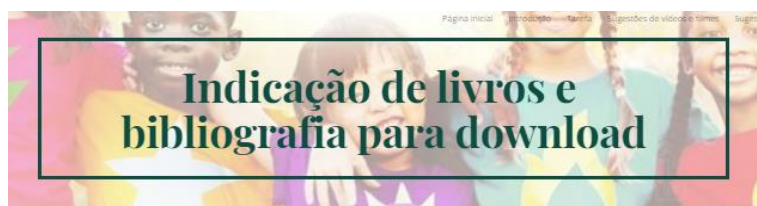

1 - Sugestões de livros e histórias para a abordagem de gênero em sala de aula:
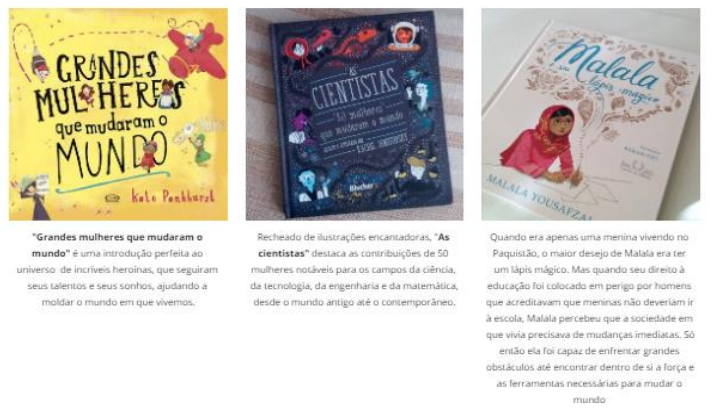

Fonte: ROSSI; FRANÇA, 2019.

As imagens acima apresentam alguns recortes da nossa WQ e exemplifica algumas das sugestões referidas no material. Cada uma das sugestões foi indicada tendo em vista a viabilidade de cada recurso em torno das questões de gênero, dentre estes podemos citar alguns dos filmes como: "Valente: a conquista de Merida", "Moana", "Mulan" e "Alice no País das Maravilhas", que oportunizam a desconstrução de estereótipos em torno do "ser mulher" e a discussão sobre o empoderamento feminino. Além disso, algumas das histórias como: "Malala e seu lápis mágico" (YOUSAFZAI, 2018); "As cientistas: 50 mulheres que mudaram o mundo" (IGNOTOFSKY, 2017) e "Frida Kahlo: para meninos e meninas" (FINK; SAÁ, 2015), por exemplo, conduzem ao reconhecimento de figuras femininas antes inviabilizadas como sujeitos da própria ciência, desigualdade esta, que vem tentando ser superada nas últimas décadas, principalmente pelo advento do movimento feminista.

Como afirmamos anteriormente, os recursos sugeridos na WQ foram imprescindiveis para a realização da "Tarefa" que propomos, uma vez que a

2 Todas as imagens utilizadas estão devidamente creditadas na página da WQ. Interfaces da Educ., Paranaíba, v.11, n.32, p. 213- 243, 2020 
mesma consistia na escolha, aplicação, debate e divulgação dos resultados obtidos por meio das experiências vivenciadas pelas educadoras com suas respectivas turmas. O enunciado da tarefa consistiu em quatro passos, expostos da seguinte maneira à/ao participante:

1 - Você verá que existe na barra acima, três últimos links intitulados: "Sugestões de vídeos e filmes"; "Sugestões didáticas" e "Indicação de livros e histórias". Sendo assim, neste primeiro momento, gostariamos que vocês explorassem estas três seções. Fique tranquilo/a, não há pressa! Retorne a Webquest quantas vezes for necessário a você!

2 - Após explorar os três links sugeridos acima, você professor/a, deve escolher uma das sugestões de trabalho indicadas, pode ser: uma dinâmica, um livro infantil, um vídeo ou um dos filmes indicados.

3 - Já escolheu? Agora você terá a tarefa de aventurar-se com seus alunos e alunas sob a temática de gênero. Reserve um tempo no cronograma de sua turma e aplique o recurso que você escolheu. Não esqueça de reservar um tempo final para debate daquilo que foi aplicado.

4 - Compartilhe com seus/suas colegas educadores/as a experiência vivenciada por você em sala de aula, como: o que avaliou da atividade aplicada? Houve aspectos positivos e/ou negativos? Quais foram as dúvidas da turma? Quais foram as contribuições dos/das alunos/as? Como você se sentiu com a realização desta atividade? Mudaria alguma coisa? Indicaria esta tarefa para outros/as professores/as? (ROSSI; FRANÇA, 2019, s/p).

Como pode ser observado, primamos que a/o educadora/or pudesse escolher o recurso que a/o deixasse mais confortável para abordar com suas/seus alunas/os, tendo em vista que muitas/os docentes ainda têm receios ou não possuem a devida formação para abordar esta temática efetivamente. Acreditamos que seria pertinente deixar o caminho mais aberto para que optassem por aquilo que ponderassem como uma possibilidade de discussão que estivesse ao seu alcance. Por isso, buscamos apresentar uma gama de materiais possíveis, a fim de que a/o educadora/or pudesse vislumbrar várias alternativas para realizar este trabalho.

Entretanto, entendemos que a construção e a mera disponibilização da WQ Gênero e Diversidade na Escola não seriam suficientes para que as/os professoras/es buscassem por conta própria a utilização do material, o que poderia cunhar no desuso da WQ. Assim, seria necessário um trabalho de sensibilização, ou seja, "propor oficinas especificamente voltada Interfaces da Educ., Paranaíba, v.11, n.32, p. 213- 243, 2020 
para gênero [...] devido à sua complexidade e ao que é preciso fazer para compreender e transformar as relações de gênero" (FIGUEIRÓ, 2014, p. 334335).

Neste sentido, além de disponibilizar o link da WQ que construímos para acesso de todas/os as/os educadoras/es interessadas/os, percebemos também a necessidade de ofertar um curso durante a semana de formação continuada de professoras/es de um dos municípios da microrregião de Campo Mourão, a fim de evidenciar a relevância das discussões de gênero dentro das práticas pedagógicas e capacitá-las/os à utilização da WQ, como veremos a partir da próxima seção.

\section{"Mulheres na Escola": uma metodologia para o trabalho de gênero: o curso de formação continuada e a proposta-convite de aplicação}

A fim de instrumentalizar as/os professoras/es atuantes da rede básica de ensino do município de Iretama, estado do Paraná, para o trabalho com a temática de gênero por meio da WebQuest Gênero e Diversidade na Escola, realizamos o curso intitulado "Mulheres na Escola: uma metodologia para o trabalho de gênero". Foi ministrado durante a semana de Formação Continuada do município, ocorrida no início do primeiro semestre de 2019. Partindo do entendimento do conceito de "formação", segundo Figueiró (2014, p. 105) a formação continuada, refere-se às "propostas ou ações (cursos, estudos, reflexões...) voltadas, em primeira instância, para aprimorar a prática profissional do professor". Com o intuito de dialogarmos com as/os docentes sobre o uso da WQ e, concomitantemente, conduzirmos à reflexão acerca da importância da inserção de questões de gênero nas práticas pedagógicas, estruturamos nossa abordagem com as/os professoras/es em dois momentos.

Em um primeiro momento, iniciamos nossa fala com uma reflexão em torno da desigualdade de gênero a partir de uma situação de violência contra a mulher na atualidade, com o vídeo: “'Sozinhas' - Violência contra mulheres 
que vivem no campo"3. Em seguida, realizamos a explanação teórica acerca da temática de gênero, no qual expomos o histórico das discussões de gênero atrelado à luta do movimento feminista, movimento que é caracterizado como Primeira, Segunda e Terceira Ondas (LOURO, 1997; MEYER, 2013). Apresentamos também os significados dos conceitos de gênero, sexo e sexualidade e suas diferenciações, bem como os equívocos que têm cercado a temática, e aquilo que tem sido propagado atualmente pelo termo "ideologia de gênero" (GONÇALVES; MELLO, 2017).

Por fim, consideramos relevante apresentar personagens femininas que fazem parte da História, como: Frida Kahlo (artista) e Hipátia (astrônoma, matemática e filósofa), a fim de atribuir notoriedade à produção de grandes mulheres que contribuíram no ramo da ciência, da cultura e das artes, mas que ainda continuam invisibilizadas no espaço escolar e são desconhecidas e/ou ignoradas pelas/os professoras/es.

Compreendemos a importância deste primeiro momento, uma vez que apresentar a ferramenta e não levar as/os docentes à refletirem sobre a importância de discutirem as questões de gênero na escola, dificulta o próprio uso da WQ por nós proposta, pois temáticas que não têm o seu devido reconhecimento pela/o professora/or, tendem a ser pouco valorizadas pelas/os mesmas/os, tal como é discutido por Leite (2015, p. 115):

[...] os 'materiais de apoio' são recursos de suma importância, mas não o suficiente para o trabalho consistente de gênero e de sexualidade no espaço educativo. Ter acesso ao material e o conhecimento teórico ser superficial e/ou distorcido pelas compreensões biológicas não adianta muito porque consideramos que, por trás de uma ampla ação pedagógica (que problematize as práticas sociais e as aprendizagens de gênero e sexualidade), há a necessidade de uma boa base teórica.

Desta maneira, pareceu oportuno que discutir a história do feminismo e das questões de gênero em primeiro lugar, poderia nos oferecer uma base mais sólida para que, no momento posterior, pudéssemos apresentar a ferramenta WQ.

\footnotetext{
${ }^{3}$ Disponivel em: <https://www.youtube.com/watch?v=XEuJ9XT2yX8>. Acesso em 01 de fev. 2019.
}

Interfaces da Educ., Paranaíba, v.11, n.32, p. 213- 243, 2020 
Em segundo momento, realizamos a exposição da WebQuest Gênero e Diversidade na Escola, e explicamos o que é uma WQ, seus objetivos e o intuito da ferramenta que construímos. Buscamos apresentar cada uma das seções sanando as possíveis dúvidas e exemplificando como realizar o manuseio desta metodologia. Segundo Pereira (2009, p. 22), a explanação da WebQuest visa fornecer orientações a fim de "auxiliar o professor no desenvolvimento da sua prática docente [...] explicando seus pontos essenciais, sugerindo opções de trabalho e estimulando o professor a reflexão sobre sua prática em sala de aula”.

\section{Formação continuada em Iretama-PR}
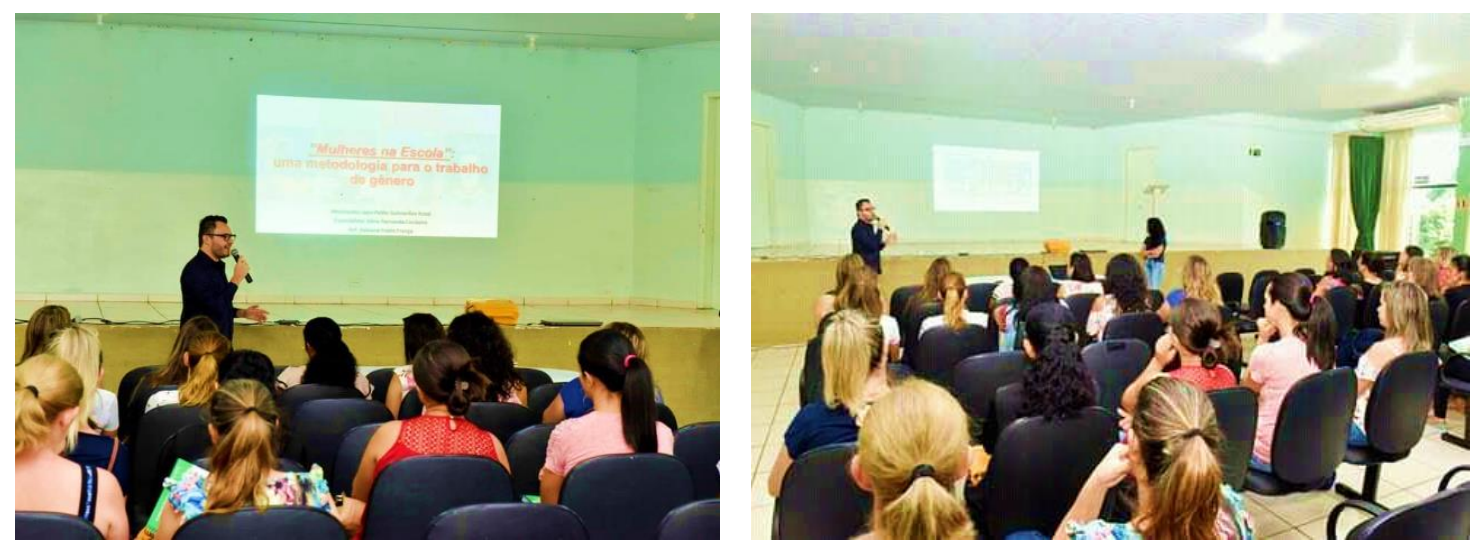

Fonte: Secretaria Municipal de Educação de Iretama (SMEI)

Após o curso de Formação Continuada, o link para o uso da WQ foi disponibilizado as/os professoras/es das escolas do município, haja vista que todas/os as/os docentes compareceram durante a semana de formação. Posteriormente, obtivemos à autorização e direcionamento da secretaria e coordenação pedagógica da SMEI para proposição de aplicação da pesquisa em uma das escolas do município. A partir da indicação da SMEI, propomos o convite para uma das escolas do município, que atende desde o $1^{\circ}$ até o $5^{\circ}$ ano da Educação Básica. Desta forma, tínhamos por intenção, analisar os resultados produzidos pela WQ Gênero e Diversidade na Escola a partir das experiências de aplicação relatadas pelas/os docentes que se dispusessem a participar da pesquisa. 
$\mathrm{Na}$ ocasião, as/os docentes foram reunidas/os em um dos dias letivos, durante o intervalo entre as aulas, para que assim pudéssemos realizar a proposta-convite visando a aplicação da WebQuest Gênero e Diversidade na Escola e o posterior preenchimento do questionário acerca das experiências com a ferramenta, obtidas pela/o professora/or participante, com suas respectivas turmas. Mediante a assinatura do TCLE (Termo de Compromisso Livre e Esclarecido) e atribuição de certificação de participação como incentivo que assegurasse maior engajamento na atividade proposta, quatro educadoras aceitaram a participação na pesquisa.

Consequentemente, tivemos como fontes de análise, os questionários de avaliação respondidos pelas professoras a partir de suas experiências com a ferramenta, que contemplou as seguintes questões:
a) Nome da/o docente;
b) Turma/Ano;
c) Atividade escolhida;
d) Este foi o seu primeiro contato com a temática de gênero em sala de aula?;
e) Qual a sua opinião em relação a WebQuest?;
f) Você considera que houve aspectos positivos na atividade realizada? Quais?;
g) Apresentou alguma dificuldade no manuseio da WQ? Se sim, quais?;
h) Houve aspectos negativos acerca da atividade aplicada? Quais?;
i) Houve contribuições/comentários da turma acerca da atividade?;
j) Quais foram as dúvidas/perguntas da turma?;
k) Tem a intenção de continuar utilizando algum dos materiais disponiveis nesta WebQuest? Quais?;
1) Indicaria esta WebQuest para outras/os professoras/es?
$\mathrm{m})$ Teria alguma sugestão para melhorar algum item desta WebQuest?

Por meio da análise das fontes, seguiremos para a próxima seção, na qual nos dedicaremos a discutir as experiências relatadas pelas participantes, buscando, assim, discutir a validade da WQ como um método possivel para as discussões de gênero nas práticas pedagógicas.

\section{Gênero e WebQuest: experiências de educadoras em debate}

Nesta seção, realizamos uma análise geral de natureza interpretativa, calcadas/os na ótica dos Estudos de Gênero, a partir das experiências das 
educadoras com a ferramenta WQ Gênero e Diversidade na Escola, viabilizadas a nós, por meio dos questionários respondidos pelas mesmas. A aplicação da WQ foi realizada por quatro docentes, mulheres, atuantes no $2^{\circ}, 3^{\circ}$ e $5^{\circ}$ ano do Ensino Fundamental de uma Escola Municipal. Como forma de manter suas identidades sob sigilo, quando necessário, serão identificadas neste estudo por "P" (participante), sucedido por um número de identificação:

\begin{tabular}{|c|c|c|c|c|}
\hline $\begin{array}{c}\text { Identificação } \\
\text { da } \\
\text { participante }\end{array}$ & P1 & P2 & P3 & P4 \\
\hline Ano/Turma & $2^{\circ}$ & $3^{\circ}$ & $5^{\circ}$ & $5^{\circ}$ \\
\hline
\end{tabular}

De antemão, consideramos plausível nos atentarmos ao fato de que apenas quatro professoras, de um total de vinte docentes, concordaram com a aplicação da WQ, o que denota uma certa dificuldade e resistência para que as/os docentes compreendam que as questões de gênero devam ser debatidas dentro da escola. Por essas razões, há a necessidade do investimento sobre a formação docente, a fim de que as/os educadoras/es possam trabalhar seus próprios estigmas, preconceitos e crenças pessoais, que geram tal resistência, para que, posteriormente, sintam-se preparadas/os para abarcar as questões de gênero em suas práticas pedagógicas.

Além disso, a baixa adesão de participantes também pode ser compreendida pelo próprio déficit sobre o uso de tecnologias no espaço educacional, o que pode ter sido um gerador de resistência pelas/os docentes que não anuíram com a aplicação, uma vez que a presença das TIC (Tecnologias de informação e comunicação) pode sinalizar uma saída da zona de conforto ou uma mudança de paradigma, como é sublinhado por Pimentel (2007, p. 6): 
Um dos desafios apresentados encontra-se na resistência por parte de alguns docentes, que não conseguem vislumbrar os ganhos com a mudança de paradigma. Esta resistência se dá devido ao forte vínculo às práticas de ensino-aprendizagem que por muitas vezes prendem os professores à estrutura burocrática exigida pelas secretarias dos respectivos cursos.

Outra hipótese para a baixa adesão, pode estar relacionada a falta de familiaridade com tecnologias, o que pode levá-las/os a pensar que a WQ se trata de uma tarefa muito complexa ou que não estão preparadas/os para utilizá-la, o que pode sinalizar tanto à necessidade da formação continuada, quanto a averiguação dos subsídios que têm sido oportunizados pela escola (instrumentos tecnológicos, espaço propício, profissionais adequados, etc.), que possibilitam (ou não) às/aos educadoras/es o suporte para a utilização de tecnologias.

Inicialmente, o primeiro ponto que nos chamou atenção, foi à escolha da atividade pelas docentes, pois todas optaram pelo mesmo filme dentre as opções sugeridas na WQ: "Valente", e apenas uma das participantes - P1 -, além do mesmo filme, também aplicou a dinâmica "As funções de gênero". O fato de as participantes optarem, em sua maioria, pelo mesmo recurso, se deu em função da mobilização coletiva que estava acontecendo neste mesmo período entre as/os professoras/es, em alusão aos trabalhos referentes ao dia 18 de maio, data marcada pelo Dia Nacional de Combate ao Abuso e à Exploração Sexual de Crianças e Adolescentes.

Desta maneira, quando pensamos no trabalho de gênero atrelado a datas pontuais como: Dia Internacional da Mulher, Dia do Orgulho Gay e/ou datas comemorativas, percebemos que se trata de uma saída que a escola encontra para abordar de forma rápida e ligeira tais questões (FURLANI, 2013; MEYER, 2013). Essas discussões são problematizadas por Dagmar Meyer (2013) e Jimena Furlani (2013), as quais discutem que a abordagem acerca da temática de gênero, apenas em situações circunstanciais, pode apontar para uma prática que ainda não é incorporada no cotidiano das discussões em sala de aula, e que continuam dando vasão as mesmas hierarquias. Portanto, entendemos que as atividades pontuais não devem ser rejeitadas, mas não devem ser as únicas, pois estas não se Interfaces da Educ., Paranaíba, v.11, n.32, p. 213- 243, 2020 
configuram como “o’ processo (em si) [...] mas como uma entre outras estratégias didáticas" (FURLANI, 2013 p. 69).

Como destacamos anteriormente, a opção de atividade escolhida pelas participantes foi a apresentação do filme "Valente". Esse, de origem estadunidense, tem como nome original "Brave", produzido pela Pixar Animation Studios e lançado em 2012. Recebeu o Oscar de Melhor Longa Animado, em 2013. Em suma, o roteiro retrata a história de Merida, uma menina que se recusava a seguir os padrões e regras impostos a ela por sua mãe, a rainha. A mãe insistia para que a filha aceitasse um dos pedidos de casamento de um dos príncipes do reino em que vivia e, enfim, se tornasse uma princesa, nos moldes da época. Entretanto, este não era o desejo de Merida, e sim, se tornar uma guerreira, fazer suas escolhas e decidir o seu próprio destino (LAUX, 2016). Segundo Laux (2016, p. 6), este filme possui características interessantes que, podem possibilitar algumas problematizações, tais como:

[...] Apresentar uma mulher como protagonista; pelo seu enredo, que contém elementos relacionados a questões discutidas pelos estudos de gênero; e, principalmente, por possibilitar um debate interessante ao mostrar outro modelo de feminilidade não convencional em filmes de princesas, uma vez que o filme poderia proporcionar questionamentos a respeito dos comportamentos esperados e não tão esperados para meninos e meninas (LAUX, 2016, p. 6).

Deste modo, compreendemos que a escolha deste filme como estratégia didática se justifica por seu caráter lúdico, problematizador e nãoconvencional. A partir de suas experiências, as participantes da pesquisa destacaram que as/os alunas/os puderam confrontar-se com os estereótipos e padrões de "masculino e feminino", bem como os papéis socialmente designados para homens e mulheres, conforme foi relatado por duas educadoras:

P3: Puderam expor suas opiniões e confrontar com ideias presas ao passado, trocando assim experiências [...] confrontaram muito o papel da mulher hoje na sociedade e como era vista no passado. 
P1: A turma deu opiniões contrariando pensamentos "machistas", falaram de como respeitar as pessoas de acordo com seus gostos, por exemplo, um menino que gosta de brincar com bonecas, uma menina que gosta de brincar de carrinhos, etc.

Como pôde ser observado acima, mediante os questionamentos levantados pelas alunas e alunos acerca das funções, papéis e igualdade de gênero, destacamos a problematização feita por Chimamanda Ngozi Adichie (2017), em que a autora sublinha o quanto os estereótipos de gênero tendem a funcionar como "camisas de força" que limitam meninas e meninos a determinados comportamentos, atitudes esperáveis, modos não esperáveis e outros padrões hegemônicos, que geralmente se impõem por meio de afirmações simplistas, como: "porque você é menino" ou "porque você é menina”. “Porque você é menina' nunca é razão para nada. Jamais” (ADICHIE, 2015, p. 21).

É por esse viés que o filme "Valente" acaba por subverter a regra, uma vez que a personagem não se enquadra na figura idealizada de princesa, geralmente atrelada a características como "bonita, linda, educada, cabelos lindos, querida, contos de fadas, vestidos longos, coroa, mora num castelo, casa com príncipe" (LAUX, 2016, p. 8), sendo que os outros adjetivos com os quais a protagonista mais se identificava, tais como: valente, corajoso, destemido, audacioso e ousado, são comumente atrelados à figura masculina. Mediante a tais representações de gênero, Louro (2013, p. 48), sugere que uma estratégia mais desestabilizadora problematizará:

[...] por exemplo, o fato de as mulheres serem denominadas de "o segundo sexo" (uma afirmativa que é, via de regra, consensual e indiscutível) e levará a analisar as narrativas - religiosas, históricas, científicas, psicológicas - que instituíram este lugar para o feminino (LOURO, 2013, p. 48).

É pensando nas indagações e reflexões oriundas das discussões de gênero que destacamos outro ponto levantado pelas participantes, as quais também ressaltaram um engajamento maior por parte dos meninos das turmas, uma vez que os mesmos expressaram concordâncias e discordâncias mediante as discussões em torno das funções atribuídas a 
homens e mulheres, como pode ser observado em alguns dos comentários abaixo:

P1: Teve alunos meninos, (a minoria), que não concordam que o homem também pode fazer as atividades domésticas, que isso é papel da mulher, e quando eles crescessem eles não iriam fazer alguns afazeres domésticos.

P2: Questionaram quanto a príncipes encantados, pois não havia na história $[\ldots]$

P3: [...] pude analisar uma reflexão principalmente por parte dos meninos.

A partir dos comentários acima, analisamos que os meninos são criados de maneira nociva, pensando nas especificidades do gênero masculino, pois a definição de masculinidade é muito estreita, o que faz com que acabem fixando padrões rígidos e ao mesmo tempo frágeis sobre o "ser homem". "Abafamos a humanidade que existe nos meninos, enclausurandoos numa jaula pequena e resistente. Ensinamos que eles não podem ter medo, não ser fracos ou se mostrar vulneráveis” (ADICHIE, 2015, p. 29). Além disso, quando a educadora (P2) expõe que as/os alunas/os questionam acerca de não existirem príncipes na história, nos mostra o quanto padrões naturalizados de conduta, geram certo estranhamento quando são postos em xeque, já que a ausência de príncipes é geralmente encarada como um elemento de "falta" ou "carência" dentro de histórias com princesas protagonistas. São estes alguns padrões de gênero desiguais e que (de)limitam os lugares supostamente "próprios" para meninas e para meninos. Neste sentido, Castro (2018, p. 77) destaca a urgência de levarmos a tônica deste debate para a escola:

Precisamos urgentemente problematizar os pressupostos que corroboram a tese de que haveria uma expressão de gênero fixa para cada sexo e que essa expressão de gênero reflete uma 'subjetividade', uma identidade, também fixa, ou masculina, ou feminina. Presentes desde cedo na criação e educação de crianças e jovens, esses pressupostos hoje, mais do que nunca, geram mais violência e desordem. Precisamos falar sobre formas de combater modelos de 
masculinidades tóxicas, pois estas não são só prejudiciais às mulheres, elas prejudicam os próprios homens.

Se a nossa cultura ensina desde cedo às meninas que o lugar delas é cuidando dos afazeres domésticos, o mesmo não acontece com os meninos. Quando crescerem, estas mesmas meninas, possivelmente, se casarão com estes homens. Consequentemente, iremos nos deparar com a grande quantidade de mulheres sofrendo em detrimento do casamento, uma vez que esta instituição tem mais importância a elas do que ao cônjuge (ADICHIE, 2015; 2017; CASTRO, 2018). Tal fato foi percebido por algumas das participantes, as quais expuseram que, as/os alunas/os dialogaram nos debates trazendo com aspectos de suas realidades, como o fato de notarem a polarização das funções entre as mães e os pais:

P1 - Sim, houve muitos comentários, pude perceber que na maioria das famílias da turma, as crianças relatam que cabe a mãe cuidar da casa e dos afazeres domésticos, mesmo a mãe trabalhando fora, elas que trabalham mais cuidando da casa também, e que eles (as crianças), não concordam com isso, mas que o pai (homem) não leva jeito pra esse tipo de serviço.

P4: Levou os alunos a pensar e debater sobre as diferenças entre meninas e meninos. E ao mesmo tempo a igualdade e os direitos de escolha.

A partir dos comentários acima, podemos analisar que quando as crianças ressaltam que a figura da mãe, mesmo trabalhando fora, ainda necessita desdobrar maiores esforços também nos afazeres domésticos, e, ao pai, esta realidade não se apresenta da mesma maneira, pois o mesmo "não leva jeito pra esse tipo de serviço", entendemos que há aqui uma construção social fortemente arraigada que expressa o quanto à normalidade e a diferença são produtos socialmente e culturalmente produzidos como tais (LOURO, 1997; FURLANI, 2008; MEYER, 2013). Desta maneira, se discursos como estes, que legitimam a compreensão de que homens "naturalmente" não apresentariam habilidades para atividades domésticas não são questionados, problematizados e descontruídos, podemos incidir no risco de 
perpetuar as mesmas naturalizações e desigualdades. Neste sentido, sob esta mesma perspectiva, França (2017, p. 120) destaca que,

\begin{abstract}
As pessoas ouvem, assistem, falam de si e do outro de uma maneira tão naturalizada que forçam práticas preconceituosas, androcêntricas, sexistas, dentre outras centradas em um discurso normatizador ancorado em práticas sociais históricas. Investigar, dialogar e problematizar estas práticas pode nos possibilitar um posicionamento político que não mais tolere e aceite ações como essas (FRANÇA, 2017, p. 120).
\end{abstract}

A partir das respostas explanadas pelas participantes, percebemos que as experiências estão em consonância com alguns dos intuitos da WebQuest, pois a ferramenta "deve possibilitar ao aluno oportunidade para que elabore suas próprias hipóteses e teorias, recrie seus próprios conceitos com base no questionamento do problema que se apresenta" (ROCHA, 2007, p. 109). Além disso, como temos notado, indagações foram suscitadas a partir das aplicações realizadas pelas educadoras, dando vasão à novas reflexões, dentre elas: acerca dos estereótipos de gênero, o empoderamento feminino e a equidade de gênero. Com fundamento nestas experiências pedagógicas, compreendemos que há concomitantemente ao trabalho com as/os alunas/os, um aprimoramento na formação docente, haja vista que a formação da/o professora/or não se dá alheia à sua atividade pedagógica, pelo contrário, se desenvolve continuamente, em paralelo às práticas cotidianas. Em outras palavras,

\begin{abstract}
o conhecimento do professor profissional forma-se principalmente sobre a experiência, onde o estudante pode experimentar a ação e a reflexão em situações reais [...] a partir de situações práticas como o elemento principal da formação de profissionais [...] o exercício reflexivo permite ao profissional vivenciar e sair bem-sucedido de situações novas e desafiadoras no ambiente de trabalho, possibilitando a reflexão durante todo o processo de atuação pedagógica do professor (ROCHA, 2007, p. 18).
\end{abstract}

Todas as participantes responderam que indicariam a WebQuest Gênero e Diversidade na Escola para outras/os professoras/es e a consideraram muito prática e objetiva, sendo que nenhuma delas alegou 
alguma dificuldade quanto ao seu manuseio. Em relação a intencionalidade para prosseguirem trabalhando com a WQ, três participantes responderam que pretendem continuar trabalhando com a metodologia e, apenas uma (P2), respondeu que recorrerá a WQ, somente caso avalie necessário. Neste sentido, segundo Pereira (2009, p. 16), o fato da/o profissional retornar à WQ pode se configurar como uma estratégia válida no sentido de averiguar a teoria e prática, permitindo (re)avaliar as "possibilidades e dificuldades encontradas, alimentando assim novos debates". Por último, gostaríamos de problematizar um dos comentários realizados por uma das participantes, como segue abaixo:

P4: Vocês estão de parabéns. Já deixaram a nossa disposição uma pesquisa nesta área que pode enriquecer nossas aulas neste contexto tão peculiar, que muitos professores não enxergam como necessário. É preciso levar nossos alunos a terem um olhar de igualdade sem preconceito diante da ideologia de Gênero (grifo nosso).

No comentário acima, apesar de tecer alguns elogios a pesquisa, ao material e a nós pesquisadoras/es, a participante acabou reproduzindo a expressão "ideologia de gênero". O termo não está presente em nenhum dos Estudos Feministas ou Estudos de Gênero e surgiu no interior dos discursos políticos e religiosos, cunhado pelas/os detratoras/es e opositoras/es da temática a fim de apresentá-la equivocadamente como um tema que supostamente visa corromper meninas e meninos, deturpar princípios morais e os padrões heteronormativos (GONÇALVES; MELLO, 2017). Tal fato nos mostra o quanto existem aspectos que acabam escapando da formação docente ou que, "extrapolam a formação acadêmica" (MARTELLI, 2011, p. 27), tendo em vista que, tanto no curso ofertado durante a Formação Continuada, quanto no próprio conteúdo da WQ que disponibilizamos, foram abordados os equívocos acerca deste termo "ideologia de gênero". Entretanto, ainda foi reproduzido pela participante.

Além disso, a reprodução do pseudo conceito "ideologia de gênero", novamente reforça o quanto as/os professoras/es não estão eximes de Interfaces da Educ., Paranaíba, v.11, n.32, p. 213- 243, 2020 
reprodução de concepções e crenças particulares no espaço escolar, uma vez que ela expressa um termo que foi propagado midiaticamente e que vai contra o trabalho de gênero em sala de aula, ou seja, as educadoras estão ouvindo as informações difundidas pelos diversos meios de comunicação, mas não estão recebendo a devida formação para que possam abordar a temática, pelo contrário, ainda repercutem as denominadas "pedagogias culturais" (ANDRADE, 2013; ALÓS, 2011) em suas práticas pedagógicas.

Tendo este fator em vista, entendemos o quão necessário é abrir espaço para as discussões de gênero na escola, principalmente para problematizar preconceitos, estigmas e "verdades naturalizadas", mas que, sobretudo, "é preciso antes o/a adulto/a compreender e problematizar seus próprios preconceitos" (FRANÇA, 2017, p. 124). Desta maneira, dá-se aqui a necessidade de (re)pensarmos a formação das/os docentes, pois a "insegurança causada pela falta de conhecimento ou domínio dos recursos compromete os objetivos de uma proposta de trabalho" (PEREIRA, 2009, p. 33) que possa se apresentar de forma mais efetiva.

É nesse sentido que a WebQuest se mostra como uma das estratégias possiveis atualmente, no sentido de oferecer subsídios teóricos e práticos à/ao professora/or que, por vezes, sente-se desemparada/o pela falta de formação teórico-prática em torno da temática. Além disso, compreendemos também que formar as/os alunas/os e as/os professoras/res não é um processo dicotômico, ao contrário, deve(ria) acontecer de forma articulada, pois se a própria escola é encarada como um espaço de formação, então "a troca de experiências produz espaço para reflexão e consolida o pensamento coletivo, na medida em que podem ser percebidas situações problemáticas comuns" (ROCHA, 2007, p. 17).

\section{Considerações finais}

A partir das experiências relatadas pelas educadoras participantes desta pesquisa, pudemos perceber que a WQ pode se mostrar como uma metodologia instigante, no sentido de favorecer com que as/os docentes sejam impulsionadas/os para incorporar as discussões de gênero em suas Interfaces da Educ., Paranaíba, v.11, n.32, p. 213-243, 2020 
práticas pedagógicas. Além disso, a facilidade e a objetividade da WQ, descritas pelas próprias participantes, podem ser compreendidas como pontos favoráveis para que continuem utilizando este material no cotidiano de suas salas de aula, tendo em vista que muitas/os professoras/es, por vezes, desistem de colocar em prática algum projeto articulado à algum tipo de tecnologia, pois sentem-se coibidas/os mediante as dificuldades enfrentadas em sua utilização.

Consideramos pertinente também notar que a atividade realizada pelas educadoras proporcionou algumas reflexões em torno da desigualdade de gênero, do empoderamento feminino e a desconstrução de alguns estereótipos. Entretanto, ainda assim, visualizamos alguns entraves, como o fato da temática ainda não se configurar como uma atividade sistematizada e articulada em suas atividades profissionais. Exemplo disso, é o fato de terem associado à proposta da WQ à uma data pontual, o que não pode ser caracterizado como inválido, mas uma atividade ligeira e desarticulada das práticas pedagógicas cotidianas.

Além disso, o uso que uma das participantes fez do termo "ideologia de gênero", nos aponta para a urgência de problematizar no cerne da formação docente, os estigmas, preconceitos e dúvidas que as/os educadoras/es apresentam em relação as questões de gênero. Compreendemos que a WQ pode ser uma iniciativa interessante e alternativa, no sentido de oferecer subsídios para a prática da/o docente que se encontra em um nível inicial de contato com a temática. Assim, a WQ Gênero e Diversidade na Escola não pretende ser a única, muito pelo contrário, entendemos que ela pode ser a porta de entrada para o surgimento de novas propostas de WQ que venham a contribuir no debate para as questões de gênero. Por isto, atualmente temos nos dedicado a divulgação desta WQ em cursos de formação docente e eventos científicos, bem como a mesma se encontra disponivel online para acesso de quem possa se interessar. 


\section{Referências}

ADICHIE, Chimamanda Ngozi. Para educar crianças feministas: um manifesto. Tradução: Denise Bottmann. Sâo Paulo: Companhia das Letras, 2017.

Sejamos todos feministas. Tradução: Denise Bottmann. São Paulo: Companhia das Letras, 2015.

ALÓS, Anselmo Péres. Gênero, epistemologia e performatividade: estratégias pedagógicas de subversão. Estudos Feministas, Florianópolis, v.19, n.2, p.421-449, maio/ago, 2011.

ANDRADE, Sandra dos Santos. Mídia impressa e educação dos corpos femininos. In: LOURO, Guacira Lopes; FELIPE, Jane; GOELLNER, Silvana Vilodre. Corpo, Gênero e Sexualidade: um debate contemporâneo na educação. Petrópolis/Rio de Janeiro: Vozes, 2013. p.109-123.

CASTRO, Susana de. O papel das escolas no combate às masculinidades tóxicas. APRENDER - Caderno de Filosofia e Psicologia da Educação, v. 12, n. 20, p. 75-82, jul./dez., 2018.

BOTTENTUIT JUNIOR, João Batista; COUTINHO, Clara Pereira. Recomendações de qualidade para o processo de avaliação de WebQuests. Ciências \& Cognição, v.17, n.1, p. 73 82, 2012.

FURLANI, Jimena. Educação Sexual na Escola: equidade de gênero, livre orientação sexual e igualdade étnico-racial numa proposta de respeito às diferenças. Florianópolis: UDESC (Fundação Universidade do Estado de Santa Catarina); SECAD / Ministério da Educação, 2008.

- Educação Sexual: possibilidades didáticas. In: LOURO, Guacira

Lopes; FELIPE, Jane; GOELLNER, Silvana Vilodre. Corpo, gênero e Interfaces da Educ., Paranaíba, v.11, n.32, p. 213- 243, 2020 
sexualidade: um debate contemporâneo na educação. 9. ed. Rio de Janeiro: Vozes, 2013. p. 67-82.

GONÇALVES, Eliane; MELLO, Luiz. Apresentação: gênero - vicissitudes de uma categoria e seus "problemas". Ciência e Cultura, São Paulo, v.69, n.1, p.26-30, mar. 2017.

GESSER, Marivete; OLTRAMARI, Leandro Castro; PANISSON, Gelson. Docência e concepções de sexualidade na educação básica. Psicologia \& Sociedade, v. 27, n. 3, p. 558-/568, 2015.

FINK, Nadia; SAÁ, Pitu. Frida Kahlo: para meninas e meninos. Florianópolis: Chirimbote, 2015.

FRANÇA, Fabiane Freire. Os estudos de gênero na Educação Básica: intervenção pedagógica na formação docente. 1.ed. Curitiba: CRV, 2016.

. Para que discutir gênero nas Práticas Pedagógicas? A Escola como Espaço de Diálogo. In: PAIVA, Valdemir; LIMA, Wallas Jefferson (Orgs.). Gênero e práticas culturais: debates contemporâneos. 1. ed. São Paulo: Todas as Musas, 2017. p. 113-132.

IGNOTOFSKY, Rachel. As cientistas: 50 mulheres que mudaram o mundo. São Paulo: Blucher, 2017.

LAUX, Lara Cristina Pereira. Quem pode ser Valente? As relações de gênero em representações atribuídas por crianças na escola. In: Anais do XV Seminário Internacional de Educação: Educação e Interdisciplinaridade Percursos Teóricos e Metodológicos. Universidade FEEVALE, 2016, p. 114. Disponível em: < https://www.feevale.br/Comum/midias/936b4506c995-49d5-a32 1 491ee3dcf5c4/Quem\%20pode\%20ser\%20valente\%20As\%20rela\%C3\%A7\%C Interfaces da Educ., Paranaíba, v.11, n.32, p. 213-243, 2020 
3\%B5es\%20de\%20g\%C3\%AAnero\%20em\%20representa\%C3\%A7\%C3\%B5es \%20atribu\%C3\%ADdas\%20por\%20crian\%C3\%A7as\%20na\%20escola\%20.pd f>. Acesso em 21 de jul. 2016.

LEITE, Lucimar da Luz. Representações de gênero e de sexualidade nas brincadeiras infantis e na docência: discurso, consolidação, resistência e ambivalência. 141f. Dissertação (mestrado) - Universidade Estadual de Maringá, Programa de Pós-Graduação em Educação, Maringá, 2015.

LOURO, Guacira Lopes. Educação e docência: diversidade, gênero e sexualidade. Revista Formação Docente, Belo Horizonte, v.3, n.4, p.62-70, jan./jul. 2011.

. Gênero, sexualidade e educação: uma perspectiva pósestruturalista. 6. ed. Petrópolis/Rio de Janeiro: Editora Vozes, 1997.

- Currículo, gênero e sexualidade - O "normal", o "diferente" e o "excêntrico". In: LOURO, Guacira Lopes; FELIPE, Jane; GOELLNER, Silvana Vilodre. Corpo, Gênero e Sexualidade: um debate contemporâneo na educação. Petrópolis/Rio de Janeiro: Vozes, 2013. p.43-53.

MAIO, Eliane Rose. Sexualidade, sexualidades.... In: DESIDÉRIO, Ricardo; CAMARGO, Hertz Wendel (Orgs.). Mídia, Educação e Sexualidade. Londrina/PR: Syntagma, 2011, p. 13- 15.

MARTELLI, Andréa Cristina. Práticas Docentes e Imaginários da Sexualidade. In: DESIDÉRIO, Ricardo; CAMARGO, Hertz Wendel (Orgs.). Midia, Educação e Sexualidade. Londrina: Syntagma, 2011, p. 23-42.

MEYER, Dagmar Estermann. Gênero e educação: teoria e política. In: LOURO, Guacira Lopes; FELIPE, Jane; GOELLNER, Silvana Vilodre. Corpo, 
Gênero e Sexualidade: um debate contemporâneo na educação. RJ: Vozes, 2013. p. 11-29.

NASCIMENTO, Éder Dias do. A metodologia WebQuest na aula de História. 128f. UNESPAR - Universidade Estadual do Paraná, Programa de Mestrado Profissional em Ensino de História - PROFHISTÓRIA, Campo Mourão, 2018.

PEREIRA, Rosimary Wagner. Webquest: Ferramenta Pedagógica para o Professor. Portal Dia-a-dia Educação, Paraná, Programa de desenvolvimento educacional (PDE), p. 1-52, 2009.

PIMENTEL, Fernando Silvio Cavalcante. Formação de Professores e Novas Tecnologias: possibilidades e desafios da utilização de webquest e webfólio na formação continuada. 2007. Disponível em:

<https://www.researchgate.net/profile/Fernando_Pimente19/publication/26 6291850_Formacao_de_Professores_e_Novas_Tecnologias_possibilidades_e_d esafios_da_utilizacao_de_webquest_e_webfolio_na_formacao_continuada/link s/5b603cbea6fdccf0b202be60/Formacao-de-Professores-e-NovasTecnologias-possibilidades-e-desafios-da-utilizacao-de-webquest-e-webfoliona-formacao-continuada.pdf>. Acesso em: 13 de jul. 2020.

ROCHA, Luciano Roberto. A concepção de pesquisa no cotidiano escolar: possibilidades de utilização da metodologia WebQuest na educação pela pesquisa. 2007. Dissertação (Programa de Pós-Graduação em Educação) Universidade Federal do Paraná, Curitiba, 2007.

SILVA, Nataniel Mendes; BOTTENTUIT JUNIOR, João Batista. Uma Proposta de Uso da Metodologia WebQuest para o Ensino e Aprendizagem de Literatura. Novas Tecnologias da Educação, v.12, n.1, p.1-10, jul. 2014. 
YAZLLE, Elisabeth Gelli; FERNANDES, Juliana G. D. A presença de idéias higienistas e compensatórias na formação de professores para a educação infantil. Educação, Porto Alegre, v. 32, n.2, p.201-209, maio/ago. 2009.

YOUSAFZAI, Malala. Malala e seu lápis mágico. São Paulo: Companhia das Letrinhas, 2018.

Link de acesso a WebQuest Gênero e Diversidade na Escola: ROSSI, Jean Pablo Guimarães; FRANÇA, Fabiane Freire. WebQuest Gênero e Diversidade na Escola. Disponivel em: $<$ https://sites.google.com/view/gnero-e-formao-docente/p\%C3\%A1 ginainicial>. 